\title{
Increase in albumin by daclatasvir/ asunaprevir therapy is correlated with decrease in aspartate transaminase
}

\author{
Toshiki Kan, Senju Hashimoto, Naoto Kawabe, Takuji Nakano, \\ Kazunori Nakaoka, Kentaro Yoshioka \\ Department of Liver, Biliary Tract and Pancreas Diseases, \\ Fujita Health University, Aichi 470-1192, Japan
}

\begin{abstract}
Objective: To elucidate the mechanism of an increase in the albumin levels by daclatasvir (DCV)/asunaprevir (ASV) therapy, we assessed the factors associated with an increase in the albumin levels. Methods: We retrospectively analyzed 125 patients with chronic hepatitis $C$ virus (HCV) infection, treated with DCVIASV from November 2014 to January 2016. Results: Albumin levels significantly increased from $4.0 \pm 0.4 \mathrm{~g} / \mathrm{dL}$ at baseline to $4.2 \pm 0.4 \mathrm{~g} / \mathrm{dL}$ at 24 weeks after the end of treatment (EOT) $(P<0.0001)$ in 108 patients with SVR. Patients with SVR were divided into three groups according to their baseline albumin levels: group A, $\geq 4 \mathrm{~g} / \mathrm{dL}$; group B, 3.6-3.9 g/dL; and group $\mathrm{C}, \leq 3.5 \mathrm{~g} / \mathrm{dL}$. The increase in albumin levels from baseline to at 24 weeks after EOT was significantly larger in group $C(0.5 \pm 0.5 \mathrm{~g} / \mathrm{dL}$, $P<0.0001)$ and group $B(0.2 \pm 0.4 \mathrm{~g} / \mathrm{dL}, P=0.0059)$ than in group $A(0.0 \pm 0.3 \mathrm{~g} / \mathrm{dL})$. Multivariate analysis showed that aspartate transaminase (AST) levels was the only factor associated with $\geq 0.3 \mathrm{~g} / \mathrm{dL}$ increase in albumin levels in groups $\mathrm{B}$ and $\mathrm{C}(P=0.0305)$. An increase in albumin levels was significantly correlated with a decrease in AST levels $(r=0.4729, P=0.0119)$. Conclusion: DCVIASV therapy resulted in an increase in albumin levels in SVR patients, which was significantly correlated with a decrease in AST levels. It is probable that the reduction of inflammation, but not by reduction of fibrosis, mainly caused an increase in albumin levels.
\end{abstract}

Key words: daclatasvir, asunaprevir, hepatitis C virus, albumin, cirrhosis, aspartate transaminase, inflammation, sustained virological response

\section{INTRODUCTION}

Chronic hepatitis $\mathrm{C}$ virus (HCV) infection affects approximately 180 million people worldwide. HCV usually causes a chronic infection, which can result in chronic hepatitis, liver cirrhosis, and hepatocellular carcinoma (HCC). ${ }^{[1,2]}$ In Japan, approximately 1.5 million patients with hepatitis are infected with $\mathrm{HCV}$; approximately $70 \%$ of them have $\mathrm{HCV}$ genotype $1 \mathrm{~b}$, which is resistant to interferon (IFN)-based therapy.

On September 2014, Japan authorized IFN-free therapy with oral direct-acting antivirals (DAAs), daclatasvir (DCV; NS5A inhibitor) and asunaprevir (ASV; NS3/4A protease inhibitor) for patients with $\mathrm{HCV}$ genotype 1b. DCV/ASV therapy increased the sustained virological response (SVR) rate to about $90 \%$ and caused less adverse effects than IFN-based therapy. ${ }^{[3-7]}$

In Japan, DCV/ASV therapy can be administered to patients with chronic hepatitis or compensated cirrhosis with a Child-Pugh score of 6 or less, but not to those with decompensated cirrhosis with a Child-Pugh score of 7 or more. In some other countries, IFN-free therapy is authorized for patients with decompensated cirrhosis, and high SVR rates are reported with it. ${ }^{[8,9]}$

Albumin levels are one of the factors constituting the Child-Pugh score formula; they are also one of the outcome predictors 
of compensated HCV-related cirrhosis. ${ }^{[10]}$ It has been reported that IFN-free therapies can reverse liver dysfunction in decompensated patients. ${ }^{[11-14]}$ Although IFN-free therapies reportedly increase albumin levels, the mechanism of an increase in albumin levels has not been elucidated.

Here, we retrospectively assessed whether DCV/ ASV therapy improved albumin levels, and we aimed to elucidate the factors associated with an increase in albumin levels.

\section{MATERIALS AND METHODS}

\section{DCV/ASV therapy}

From November 2014 to January 2016, 125 patients with HCV genotype 1b were treated with DCV/ASV (BristolMyers KK. Tokyo, Japan) in our hospital (Table 1). None of the patients had previously received IFN-free DCV/ASV therapy. Thirty-six patients had liver cirrhosis and $23 \mathrm{had}$ a history of HCC. When serum HCV RNA was negative at 24 weeks after EOT, the patients were considered as having achieved SVR.

\section{Ethical statement}

This study was performed in strict accordance with the ethical guidelines of the Declaration of Helsinki and was approved by the Research Ethics Committee at our hospital, approval report 92 and HG14-002. All study participants provided written informed consent.

\section{Detection of resistance-associated substitutions (RASs) of L31FM/V or $\mathrm{Y93H}$}

RASs of $\mathrm{L} 31 \mathrm{~F} / \mathrm{M} / \mathrm{V}$ or $\mathrm{Y} 93 \mathrm{H}$ were detected using a polymerase chain reaction (PCR)-invader assay with substitutions-specific probes after PCR as previously reported (BML, Tokyo, Japan). ${ }^{[15]}$ When the portions of $20 \%$ or more of RASs were detected, the presence of RASs was considered to be significant.

\section{Acoustic radiation force impulse (ARFI) measurement}

The measurement of shear wave velocity (Vs) using ARFI was performed with a Siemens ACUSON S2000 (Mochida Siemens Medical Systems Co., Ltd., Tokyo, Japan). The details of ARFI measurement procedure have been described in a previous report. ${ }^{[16]}$

\section{Albumin levels}

To assess the factors associated with albumin elevation, the patients were divided into three groups according to their baseline albumin levels: group $\mathrm{A}, \geq 4 \mathrm{~g} / \mathrm{dL}$; group $\mathrm{B}$, $3.6-3.9 \mathrm{~g} / \mathrm{dL}$; and group $\mathrm{C}, \leq 3.5 \mathrm{~g} / \mathrm{dL}$.

\section{Statistical analysis}

Results are expressed as mean \pm standard deviation. Comparisons between the groups were performed using $\chi^{2}$ test or Student's $t$-test, as appropriate. The factors associated with increased albumin levels were analyzed using multiple logistic analyses. Correlations between two factors were analyzed using linear regression analysis. Statistical analyses were performed using the StatFlex version 6.0 for Windows (StatFlex, Osaka Japan). A twosided $P$-value of $<0.05$ was considered significant.

\section{RESULTS}

\section{Response to DCV/ASV therapy}

HCV RNA became negative in $92.8 \%(116 / 125)$ patients at the end of treatment (EOT) or at discontinuation. Four patients experienced a relapse after EOT. Fifteen patients discontinued the treatment; five of them discontinued due to liver damage, but achieved SVR and were included in the analysis. Seven patients discontinued treatment due to a breakthrough (two patients), appetite loss (two patients), skin eruption (one patient), or their own decision (two patients). These patients did not achieve SVR, and were included in the analysis. One patient discontinued treatment due to fatigue, one developed hepatic encephalopathy, and one developed HCC and died before the SVR assessment; these and other three patients were lost to follow-up. These six patients lost to follow-up were not included in the analysis. There was only one patient with a RAS of Y93H, who achieved SVR. Thus, we analyzed 108 of 125 $(86.4 \%)$ patients who achieved SVR and 11 who did not achieve SVR.

\section{Increase in albumin levels}

Albumin levels significantly increased from $4.0 \pm 0.4 \mathrm{~g} /$ $\mathrm{dL}$ at baseline to $4.1 \pm 0.5 \mathrm{~g} / \mathrm{dL}$ at EOT $(P=0.0152)$ and to $4.2 \pm 0.4 \mathrm{~g} / \mathrm{dL}$ at 24 weeks after EOT $(P<0.0001)$ in patients with SVR. However, the albumin levels did not significantly increase in patients who did not achieve SVR (from $4.1 \pm 0.4 \mathrm{~g} / \mathrm{dL}$ at baseline to $4.2 \pm 0.2 \mathrm{~g} / \mathrm{dL}$ at EOT and to $4.2 \pm 0.3 \mathrm{~g} / \mathrm{dL}$ at 24 weeks after EOT) (Figure 1).

Baseline albumin levels were significantly higher in group $\mathrm{A}$ than in groups $\mathrm{B}$ and $\mathrm{C}(P<0.0001)$. They were also significantly higher in group $B$ than in group $C(P<0.0001)$. In group $A$, the albumin levels did not increase significantly after DCV/ASV therapy, from $4.4 \pm 0.2 \mathrm{~g} / \mathrm{dL}$ at baseline to $4.4 \pm 0.3 \mathrm{~g} / \mathrm{dL}$ at 24 weeks after EOT. In group $\mathrm{B}$, the albumin levels significantly increased from $3.8 \pm 0.1 \mathrm{~g} /$ $\mathrm{dL}$ at baseline to $4.0 \pm 0.4 \mathrm{~g} / \mathrm{dL}$ at 24 weeks after EOT $(P=0.0039)$. In group $C$, the albumin levels significantly increased from $3.3 \pm 0.2 \mathrm{~g} / \mathrm{dL}$ at baseline to $3.7 \pm 0.5 \mathrm{~g} /$ $\mathrm{dL}$ at 24 weeks after EOT $(P=0.0026)$ (Figure 2a). 


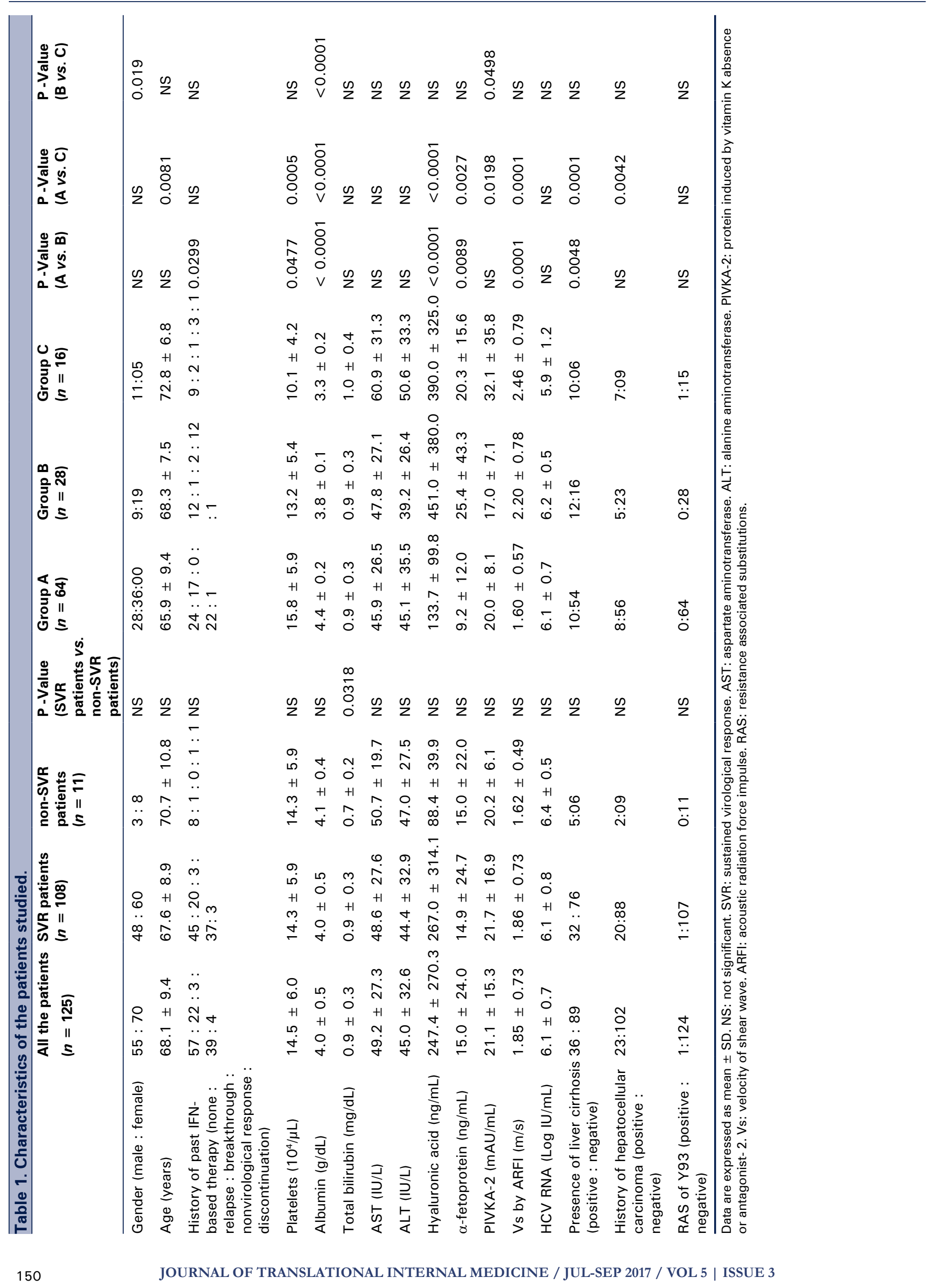


(a) SVR $(n=108)$

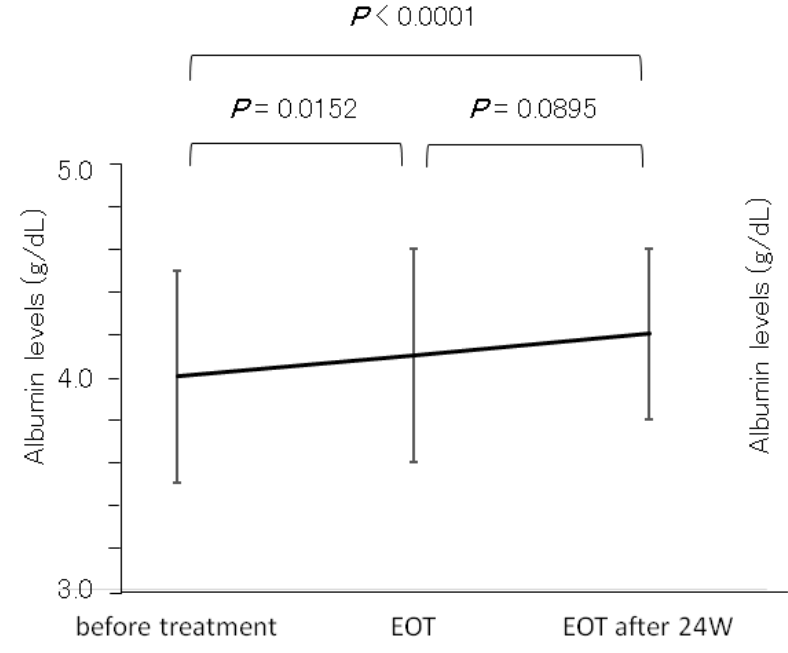

(b) non-SVR $(n=11)$

Figure 1: (a) Albumin levels significantly increased from $4.0 \pm 0.4 \mathrm{~g} / \mathrm{dL}$ at baseline to $4.1 \pm 0.5 \mathrm{~g} / \mathrm{dL}$ at the end of treatment (EOT) $(P=0.0152)$ and to $4.2 \pm 0.4 \mathrm{~g} / \mathrm{dL}$ at 24 weeks after EOT $(P<0.0001)$ in patients who achieved sustained virological response (SVR). (b) Albumin levels did not significantly increase in patients who did not achieve SVR (from $4.1 \pm 0.4 \mathrm{~g} / \mathrm{dL}$ at baseline to $4.2 \pm 0.2 \mathrm{~g} / \mathrm{dL}$ at EOT and to $4.2 \pm 0.3 \mathrm{~g} / \mathrm{dL}$ at 24 weeks after EOT).

(a) Albumin levels at baseline and at 24 weeks after EOT

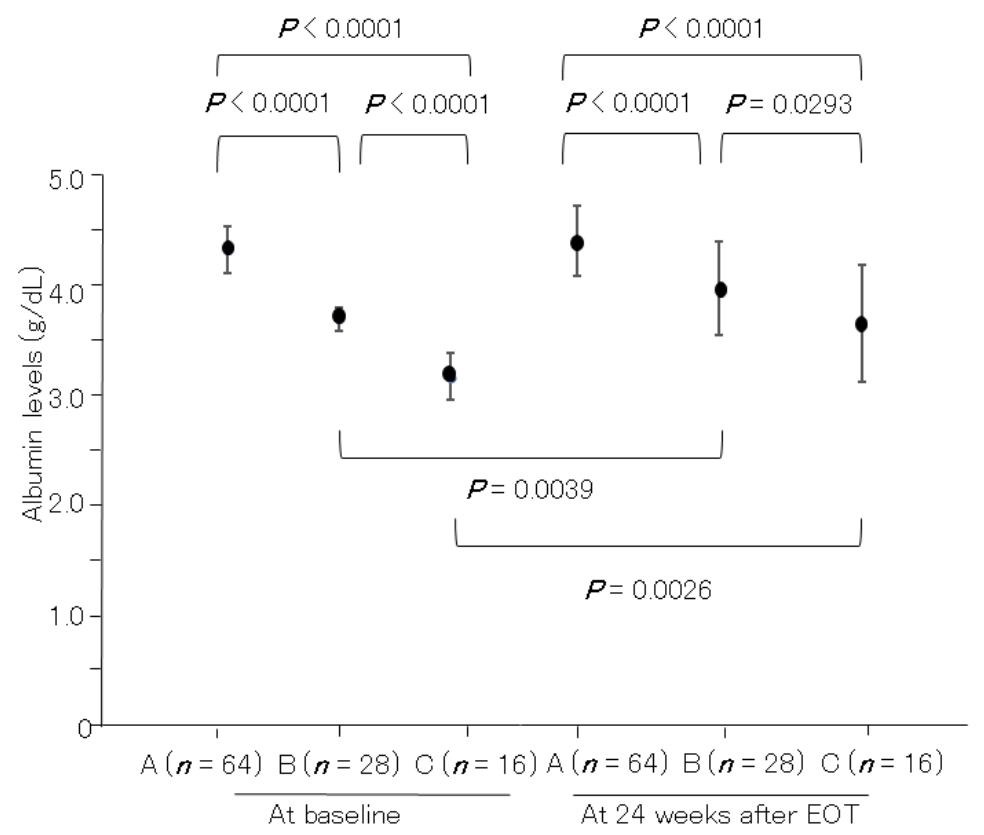

(b) The increase in albumin levels from baseline to 24 weeks after EOT

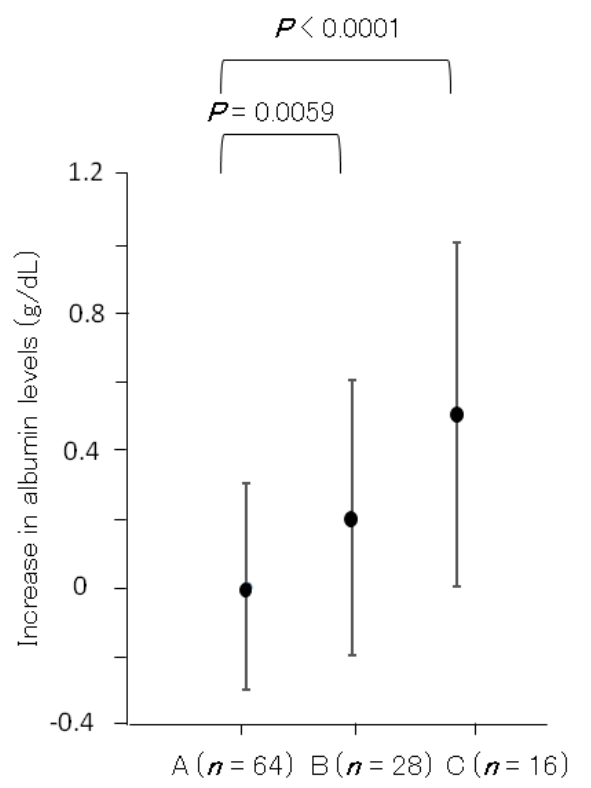

Figure 2: (a) Baseline albumin levels were significantly higher in group $A$ than in group $\mathrm{B}(P<0.0001)$ and in group $\mathrm{C}(P<0.0001)$. Baseline albumin levels were significantly higher in group $B$ than in group $C(P<0.0001)$. In group $A$, albumin levels did not increase significantly after daclatasvir/asunaprevir treatment, from 4.4 $\pm 0.2 \mathrm{~g} / \mathrm{dL}$ at baseline to $4.4 \pm 0.3 \mathrm{~g} / \mathrm{dL}$ at 24 weeks after the end of treatment (EOT). In group B, albumin levels significantly increased from $3.8 \pm 0.1 \mathrm{~g} / \mathrm{dL}$ at baseline to $4.0 \pm 0.4 \mathrm{~g} / \mathrm{dL}$ at 24 weeks after EOT $(P=0.0039)$. In group C, albumin levels significantly increased from $3.3 \pm 0.2 \mathrm{~g} / \mathrm{dL}$ at baseline to $3.7 \pm 0.5 \mathrm{~g} / \mathrm{dL}$ at $24 \mathrm{weeks}$ after EOT $(P=0.0026)$. At 24 weeks after EOT, albumin levels in group A ( $4.4 \pm 0.3 \mathrm{~g} / \mathrm{dL})$ were significantly higher than those in group $\mathrm{B}(4.0 \pm 0.4 \mathrm{~g} / \mathrm{dL} ; P<0.0001)$ and in group $C(3.7 \pm 0.5 \mathrm{~g} / \mathrm{dL} ; P<0.0001)$. They were significantly higher in group $B$ than in group $C(P=0.0293)$. (b) The increase in albumin levels from baseline to at 24 weeks after EOT was significantly greater in group C $(0.5 \pm 0.5 \mathrm{~g} / \mathrm{dL} ; P<0.0001)$ and group B $(0.2 \pm 0.4 \mathrm{~g} / \mathrm{dL} ; P=0.0059)$ than in group A (0.0 $\pm 0.3 \mathrm{~g} / \mathrm{dL})$. 
Twenty-four weeks after EOT, the albumin levels in group A $(4.4 \pm 0.3 \mathrm{~g} / \mathrm{dL})$ remained significantly higher than those in groups B $(4.0 \pm 0.4 \mathrm{~g} / \mathrm{dL} ; P<0.0001)$ and $\mathrm{C}(3.7 \pm 0.5 \mathrm{~g} / \mathrm{dL} ; P<0.0001)$ (Figure 2a). The levels were significantly higher in group $\mathrm{B}$ than in group $\mathrm{C}$ $(P=0.0293)$. The increase in albumin levels from baseline to at 24 weeks after EOT was significantly greater in groups $\mathrm{C}(0.5 \pm 0.5 \mathrm{~g} / \mathrm{dL} ; P<0.0001)$ and $\mathrm{B}(0.2 \pm 0.4 \mathrm{~g} / \mathrm{dL}$; $P=0.0059)$ than in group A $(0.0 \pm 0.3 \mathrm{~g} / \mathrm{dL}$ )(Figure $2 \mathrm{~b}$ ).

The factors associated with $\geq 0.3 \mathrm{~g} / \mathrm{dL}$ increase in albumin levels were assessed in groups B and C using univariate analysis. Higher aspartate transaminase (AST) levels $(P=0.0140)$, alanine transaminase levels $(P=0.0301)$, and Vs values measured using ARFI $(P=0.0423)$ were significantly associated with $\geq 0.3 \mathrm{~g} / \mathrm{dL}$ increase in albumin levels. Multivariate analysis showed that AST levels were the only significant factor associated with albumin elevation $(\beta=0.03546, \mathrm{SE}=0.01649, P=0.0305)$ (Table 2).
A decrease in AST levels was significantly associated with an increase in albumin levels $(r=0.4729, P=0.0119)$ (Figure 3).

\section{DISCUSSION}

The present study confirmed that DCV/ASV therapy yielded a high SVR rate $(86.4 \%)$ as previously reported. ${ }^{[3-7]}$

It has been reported that IFN-free therapy significantly increases albumin levels ${ }^{[1-14]}$. One study reported that albumin levels significantly increased only in patients with SVR, while there was no change in patients who did not achieve SVR. ${ }^{[13]}$. The present study also showed that albumin levels significantly increased in patients with SVR, but not in patients who did not achieve SVR.

Although albumin levels at 24 weeks after EOT were significantly higher in group A than in groups B and C,

\begin{tabular}{|c|c|c|c|c|c|c|}
\hline & \multicolumn{3}{|l|}{ Univariate analysis } & \multicolumn{3}{|c|}{ Multivariate analysis } \\
\hline & $\begin{array}{l}\text { Patients with albumin } \\
\text { elevation of } 0.3 \mathrm{~g} / \mathrm{dL} \text { or } \\
\text { more }(n=24)\end{array}$ & $\begin{array}{l}\text { Patients without albumin } \\
\text { elevation of } 0.3 \mathrm{~g} / \mathrm{dL} \text { or } \\
\text { more }(n=20)\end{array}$ & $P$-Value & $\beta$ & SE $(\beta)$ & $P$-Value \\
\hline Gender (male : female) & $11: 13$ & $9: 11$ & NS & & & \\
\hline Age (years) & $70.0 \pm 4.9$ & $69.8 \pm 9.9$ & NS & & & \\
\hline $\begin{array}{l}\text { History of past IFN- } \\
\text { based therapy (none : } \\
\text { relapse : breakthrough : } \\
\text { nonvirological response : } \\
\text { discontinuation) }\end{array}$ & $12: 2: 2: 7: 1$ & $9: 1: 1: 8: 1$ & NS & & & \\
\hline Platelets $\left(10^{4} / \mu \mathrm{L}\right)$ & $11.0 \pm 4.3$ & $13.3 \pm 5.9$ & NS & & & \\
\hline Albumin (g/dL) & $3.6 \pm 0.3$ & $3.6 \pm 0.3$ & NS & & & \\
\hline Total bilirubin (mg/dL) & $1.0 \pm 0.3$ & $0.9 \pm 0.4$ & NS & & & \\
\hline AST (IU/L) & $62.2 \pm 33.2$ & $41.0 \pm 17.6$ & 0.014 & 0.03546 & 0.01649 & 0.0305 \\
\hline ALT (IU/L) & $52.0 \pm 33.3$ & $33.1 \pm 19.6$ & 0.0301 & - & - & - \\
\hline Hyaluronic acid (ng/mL) & $471.9 \pm 346.6$ & $381.3 \pm 375.8$ & NS & & & \\
\hline$\alpha$-fetoprotein ( $\mathrm{ng} / \mathrm{mL}$ ) & $27.2 \pm 35.7$ & $19.5 \pm 35.0$ & NS & & & \\
\hline PIVKA-2 (mAU/mL) & $18.0 \pm 6.8$ & $28.4 \pm 33.7$ & NS & & & \\
\hline Vs by ARFI (m/s) & $2.55 \pm 0.65$ & $2.04 \pm 0.82$ & 0.0423 & 0.84931 & 0.51791 & 0.101 \\
\hline HCV RNA (Log IU/mL) & $6.2 \pm 0.5$ & $5.9 \pm 1.1$ & NS & & & \\
\hline $\begin{array}{l}\text { Presence of liver cirrhosis } \\
\text { (positive : negative) }\end{array}$ & $12: 12$ & 10:10 & NS & & & \\
\hline $\begin{array}{l}\text { History of hepatocellular } \\
\text { carcinoma (positive : } \\
\text { negative) }\end{array}$ & $7: 17$ & $5: 15$ & NS & & & \\
\hline $\begin{array}{l}\text { RAS of Y93 (positive : } \\
\text { negative) }\end{array}$ & $0: 24$ & $1: 19$ & NS & & & \\
\hline
\end{tabular}

Data are expressed as mean \pm SD. NS: not significant. SE: standard error. AST: aspartate aminotransferase. ALT: alanine aminotransferase. PIVKA-2: protein induced by vitamin $\mathrm{K}$ absence or antagonist- 2 . Vs: velocity of shear wave. ARFI: acoustic radiation force impulse. RAS: resistance associated substitutions. 
the increase in albumin levels from baseline to at 24 weeks after EOT was significantly greater in groups $\mathrm{B}$ and $\mathrm{C}$ than in group A. In group A, the baseline albumin levels were within normal range and the levels remained unchanged after achieving SVR, probably due to homeostasis, which maintains normal albumin levels. In contrast, the baseline albumin levels were lower than the normal limit in groups $\mathrm{B}$ and $\mathrm{C}$, and after achieving SVR, the levels increased, approaching the normal levels. Deterding et al. also observed that after achieving SVR, there was a marked increase in the albumin levels in patients with albumin levels below $3.5 \mathrm{~g} / \mathrm{dL} \cdot{ }^{[2]}$

Deterding et al. showed that mean albumin levels increased by $0.3 \mathrm{~g} / \mathrm{dL}$, from $3.0 \mathrm{~g} / \mathrm{dL}$ at baseline to $3.3 \mathrm{~g} / \mathrm{dL}$ at 12 weeks after EOT, in the patients with baseline albumin levels of below $3.5 \mathrm{~g} / \mathrm{dL} \cdot{ }^{[12]}$ In the present study, mean increases of albumin levels were $0.2 \mathrm{~g} / \mathrm{dL}$ in group B and $0.5 \mathrm{~g} / \mathrm{dL}$ in group C. Thus, we assessed the factors associated with $\geq 0.3 \mathrm{~g} / \mathrm{dL}$ increase in albumin levels in groups B and C. The only factor associated with $\geq 0.3 \mathrm{~g} / \mathrm{dL}$ increase in albumin levels was the baseline AST level. We also showed that a decrease in AST levels was significantly associated with an increase in albumin levels.

In healthy subjects, the albumin turnover time is approximately 25 days, and it reflects a liver albumin synthesis rate of approximately $10.5 \mathrm{~g} /$ day, balanced by renal $(6 \%)$, gastrointestinal $(10 \%)$, and catabolic $(84 \%)$ clearances ${ }^{[17]}$ Since only $20-30 \%$ of hepatocytes are committed to the production of albumin in healthy subjects, liver has a large functional reserve to increase the synthesis of albumin by 3-4 times. In cirrhosis, liver has lost this capacity. The production of albumin is mainly regulated by the osmolality and oncotic pressure, induced by hormonal factors (insulin, cortisol and growth hormone) and inhibited by acute phase cytokines, such as interleukin 6 and tumor necrosis factor $\alpha \cdot{ }^{[18]}$ Inflammation increases catabolic rate and results in hypoalbuminemia. ${ }^{[19]}$

Hypoalbuminemia in cirrhosis can be attributed mainly to the dysfunction of hepatocytes caused by fibrosis and partially to the suppression of albumin synthesis by inflammatory cytokines and increase in the catabolic rate of albumin caused by liver inflammation, which was reflected as increased AST levels. The amelioration of inflammation that suppresses albumin synthesis and increases catabolism of albumin is a reason for the association between a decrease in AST levels and an increase in the albumin levels after SVR. In groups B and C, the albumin levels at 24 weeks after EOT were still lower than those in group A. This indicates that the recovery of liver function depressed by fibrosis and destruction of functional structure may take

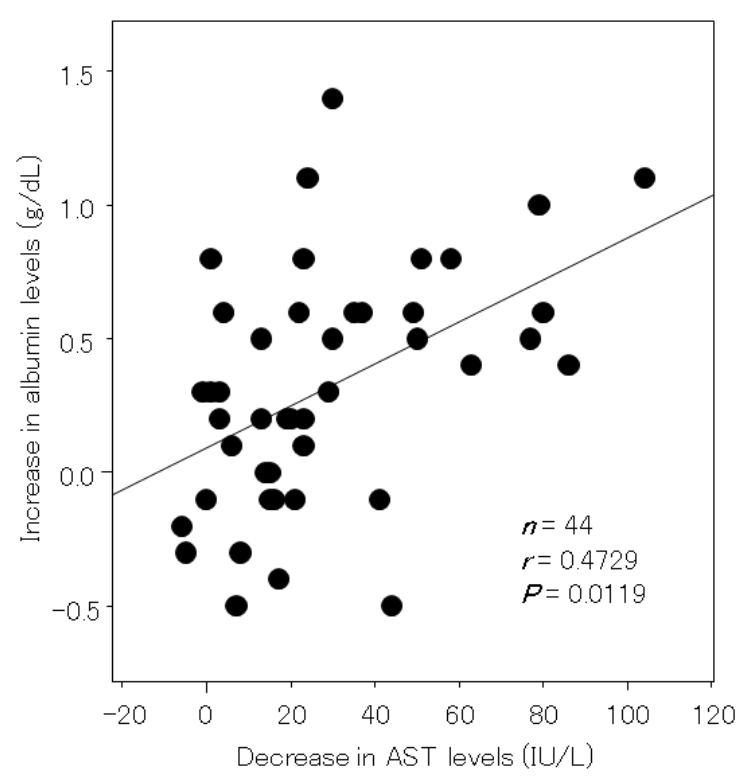

Figure 3: The decrease in aspartate transaminase (AST) levels is significantly associated with the increase in albumin levels $(r=0.4729, P=0.0119)$.

a longer period after achieving SVR.

In conclusion, DCV/ASV therapy yielded a high SVR rate and increased albumin levels in patients with SVR. An increase in albumin levels was significantly associated with a decrease in AST levels. Thus, an increase in the albumin levels can be attributed to amelioration of inflammation that suppresses liver albumin synthesis and increases the catabolic rate of albumin. However, albumin levels did not recover to within the normal range, probably because liver function is largely suppressed by fibrosis and destruction of functional structure. Recovery of albumin levels to within the normal range may take a longer period, which enables the reduction of fibrosis and recovery of functional structure.

\section{Conflicts of Interest}

The authors declare no conflict of interest.

\section{REFERENCES}

1. Niederau C, Lange S, Heintges T, Erhardt A, Buschkamp M, Hurter D, et al. Prognosis of chronic hepatitis C: results of a large, prospective cohort study. Hepatology 1998; 28: 1687-95.

2. Kiyosawa K, Sodeyama T, Tanaka E, Gibo Y, Yoshizawa K, Nakano Y, et al. Interrelationship of blood transfusion, non-A, non-B hepatitis and hepatocellular carcinoma: analysis by detection of antibody to hepatitis C virus. Hepatology 1990; 12 (4 Pt 1): 671-5.

3. Akuta N, Sezaki H, Suzuki F, Kawamura Y, Hosaka T, Kobayashi M, et al. Favorable efficacy of daclatasvir plus asunaprevir in treatment of elderly Japanese patients infected with HCV genotype $1 \mathrm{~b}$ aged 70 and older. J 
Med Virol 2017; 89: 91-8.

4. Chayama K, Takahashi S, Toyota J, Karino Y, Ikeda K, Ishikawa H, et al. Dual therapy with the nonstructural protein $5 \mathrm{~A}$ inhibitor, daclatasvir, and the nonstructural protein 3 protease inhibitor, asunaprevir, in hepatitis $\mathrm{C}$ virus genotype $1 \mathrm{~b}$-infected null responders. Hepatology 2012; 55: 742-8.

5. Kao JH, Jensen DM, Manns MP, Jacobson I, Kumada H, Toyota J, et al. Daclatasvir plus asunaprevir for HCV genotype $1 \mathrm{~b}$ infection in patients with or without compensated cirrhosis: a pooled analysis. Liver Int 2016; 36: 954-62.

6. Kumada H, Suzuki Y, Ikeda K, Toyota J, Karino Y, Chayama K, et al. Daclatasvir plus asunaprevir for chronic HCV genotype $1 \mathrm{~b}$ infection. Hepatology 2014; 59(6): 2083-2091

7. Lok AS, Gardiner DF, Lawitz E, Martorell C, Everson GT, Ghalib R, et al. Preliminary study of two antiviral agents for hepatitis $\mathrm{C}$ genotype $1 . \mathrm{N}$ Engl J Med 2012; 366: 216-24.

8. Gambato M, Lens S, Navasa M, Forns X. Treatment options in patients with decompensated cirrhosis, pre- and post-transplantation. J Hepatol 2014; 61(1 Suppl): S120-31.

9. Charlton M, Everson GT, Flamm SL, Kumar P, Landis C, Brown RS, Jr., et al. Ledipasvir and Sofosbuvir Plus Ribavirin for Treatment of HCV Infection in Patients With Advanced Liver Disease. Gastroenterology 2015; 149: 649-59.

10. Serfaty L, Aumaitre H, Chazouilleres O, Bonnand AM, Rosmorduc O, Poupon RE, et al. Determinants of outcome of compensated hepatitis $C$ virus-related cirrhosis. Hepatology 1998; 27: 1435-40.

11. Belli LS, Berenguer M, Cortesi PA, Strazzabosco M, Rockenschaub SR, Martini S, et al. Delisting of liver transplant candidates with chronic hepatitis C after viral eradication: A European study. J Hepatol 2016; 65: 524-31.

12. Deterding K, Honer Zu Siederdissen C, Port K, Solbach P, Sollik L, Kirschner J, et al. Improvement of liver function parameters in advanced
HCV-associated liver cirrhosis by IFN-free antiviral therapies. Aliment Pharmacol Ther 2015; 42: 889-901.

13. Miyaki E, Imamura M, Hiraga N, Murakami E, Kawaoka T, Tsuge M, et al. Daclatasvir and asunaprevir treatment improves liver function parameters and reduces liver fibrosis markers in chronic hepatitis $\mathrm{C}$ patients. Hepatol Res 2016; 46: 758-64.

14. Pellicelli AM, Montalbano M, Lionetti R, Durand C, Ferenci P, D’Offizi $\mathrm{G}$, et al. Sofosbuvir plus daclatasvir for post-transplant recurrent hepatitis C: potent antiviral activity but no clinical benefit if treatment is given late. Dig Liver Dis 2014; 46: 923-7.

15. Tadokoro K, Suzuki F, Kobayashi M, Kawamura Y, Sezaki H, Hosaka T, et al. Rapid and high sensitive detection of $\mathrm{Y} 93 \mathrm{H}$ amino acid substitution in HCV NS5A region using the PCR-Invader assay. Kanzo 2014; 55 : 720-2.

16. Nishikawa T, Hashimoto S, Kawabe N, Harata M, Nitta Y, Murao M, et al. Factors correlating with acoustic radiation force impulse elastography in chronic hepatitis C. World J Gastroenterol 2014; 20: 1289-97.

17. Levitt DG, Levitt MD. Human serum albumin homeostasis: a new look at the roles of synthesis, catabolism, renal and gastrointestinal excretion, and the clinical value of serum albumin measurements. Int J Gen Med 2016; 9: 229-55.

18. Quinlan GJ, Martin GS, Evans TW. Albumin: biochemical properties and therapeutic potential. Hepatology 2005; 41: 1211-9.

19. Don BR, Kaysen G. Serum albumin: relationship to inflammation and nutrition. Semin Dial 2004; 17: 432-7.

How to cite this article: Kan T, Hashimoto S, Kawabe N, Nakano T, Nakaoka K, Yoshioka K. Increase in albumin by daclatasvir/asunaprevir therapy is correlated with decrease in aspartate transaminase. J Transl Intern Med 2017; 5: 148-54. 